\title{
Assessment of adverse drug reactions to antituberculosis regimen in a tertiary care hospital
}

\author{
Sanitha Kuriachan $^{1}$, Prakash Krishnan ${ }^{1}$, Bharti Chogtu ${ }^{2}$, Manu Mathew George ${ }^{2}$
}

${ }^{1}$ Department of Pharmacology, Al Azhar Medical College, Thodupuzha, Kerala, India ${ }^{2}$ Department of Pharmacology, Kasturba Medical College, Manipal, Manipal Academy of Higher Education, Manipal, Karnataka, India

Received: 14 August 2019

Revised: 30 August 2019

Accepted: 31 August 2019

*Correspondence to:

Dr. Prakash Krishnan,

Email: drprakashkrishnan@ gmail.com

Copyright: (C) the author(s), publisher and licensee Medip Academy. This is an openaccess article distributed under the terms of the Creative Commons Attribution NonCommercial License, which permits unrestricted noncommercial use, distribution, and reproduction in any medium, provided the original work is properly cited.

\begin{abstract}
Background: Adverse drug reactions are common with multidrug therapy in tuberculosis, if detected early can improve patient compliance and prevent emergence of resistance.

Methods: A prospective observational study as a part of Pharmacovigilance Program under Central Drugs Standard Control Organisation was conducted in Kasturba hospital, Manipal to collect adverse drug reactions (ADR). Data of patients reported with antitubercular treatment (ATT) related ADRs from September 2012 to August 2013 was evaluated for patient demography, type of tuberculosis, ATT regimen, organ/ system affected and time of onset of ADR. ADRs were then subjected to causality assessment as per WHO scale.

Results: A total of 65 ADRs were reported in 60 patients during the study period, of which $46.7 \%$ were in males and $53.3 \%$ in females. $85 \%$ of ADRs were reported in patients with pulmonary tuberculosis. $77 \%$ of ADRs were observed with daily regimen. Common ADRs were hepatitis (40\%), gastritis (15\%), skin reactions (15\%), peripheral neuropathy (14\%), gout (6\%) and nephritis $(3 \%)$. Median duration for the onset of ADR was 31 days each for hepatitis, gout, nephritis and 20,11, 9 days for gastritis, peripheral neuropathy and skin reactions respectively. As per causality assessment, $80 \%$ of ADRs were assigned "possible", 11\% "probable" and 9\% "certain". As per severity scale $27.7 \%$ of ADR were severe, $36.9 \%$ were moderate.
\end{abstract}

Conclusions: Early detection and management of ADRs is vital for the success of ATT and patient adherence.

Keywords: WHO causality assessment, Pharmacovigilance, Hartwig-Siegal severity scale

\section{INTRODUCTION}

Tuberculosis (TB) is a major health problem in India accounting for $27 \%$ of the global incidences. ${ }^{1}$ Currently available multidrug anti $\mathrm{TB}$ regimen is effective for treatment of TB and latent TB infection. However, these drugs may cause adverse effects at any time during treatment. Pill burden, length of treatment, drug intolerance/toxicity lead to reduced patient compliance and contribute to the development of resistance. Given the long duration of treatment, even minor side effects must be taken seriously and it requires supervision to ensure adherence. Since severe adverse reactions may require temporary stoppage of drugs, can contribute to drug resistance. ${ }^{2}$

The modern era of tuberculosis is characterized by a rise in multidrug resistance TB (MDR-TB), which has high mortality rates compared to drug-sensitive tuberculosis. Treatment of MDR-TB is complicated and even with the best available therapy patients remains infectious for months or years. ${ }^{3}$

Since ADRs to anti-TB drugs can results in avoidable morbidity, treatment failure, reduced quality of life, or death, constant vigilance is needed to identify them at the 
earliest. $^{2}$ Therefore monitoring and reporting of adverse drug reactions is very much needed to identify the culprit drug and to tailor appropriate therapeutic regimen for the patient. ${ }^{4}$ Pharmacovigilance of antitubercular drugs is very much essential for successful treatment of tuberculosis and its elimination. ${ }^{5}$

Therefore, the present study was done to evaluate the adverse reaction profile of antitubercular treatment (ATT) and to understand the demographic and clinical profile of patients with adverse drug reactions in a tertiary care hospital.

\section{METHODS}

The present study was conducted as a part of pharmacovigilance program under department of Pharmacology, Kasturba Medical College, Manipal. This prospective observational study was conducted for a period of one year from September 2012 to August 2013. During the study period, case sheets of all the hospitalized patients with tuberculosis admitted under the Departments of general medicine and pulmonary medicine, Kasturba Hospital, Manipal, Karnataka was reviewed on daily basis and monitored for adverse drug reactions.

\section{Inclusion criteria}

Inclusion criteria were the patients diagnosed with pulmonary and extra pulmonary TB based on various clinical features and laboratory investigations; inpatients diagnosed with TB; patients of either sex with TB; patients who developed adverse reactions with ATT.

\section{Exclusion criteria}

An exclusion criterion was patients who tolerated ATT well.

When suspected adverse drug reactions were identified, the ADRs were collected from the case sheets of inpatients using Central Drug Standard Control Organization adverse drug reaction (ADR) forms. The step taken towards the management of so reported adverse drug reactions such as withdrawal of the suspected drug, dose alteration and treatment provided were also collected. The data was evaluated for patient demography, type of T.B., type of DOTS treatment, type of ADRs and Organ site/system affected. The causality and severity of ADR was assessed using WHO causality assessment scale ${ }^{6}$ and modified Hartwig and Siegel scale ${ }^{7}$ respectively.

\section{Statistical analysis}

Excel sheet and SPSS v.16 was used for statistical analysis. Demographic details of the patients were analyzed by using descriptive statistics. Continuous variables were expressed as mean \pm standard deviation and categorical variables as frequencies and percentages.

\section{RESULTS}

A total of sixty five ADRs were reported in 60 patients during the study period, of which $46.7 \%$ were in males and $53.3 \%$ in females (Table 1). Majority (85\%) of ADRs were reported in patients with pulmonary $\mathrm{TB}$ of which $12 \%$ has HIV coinfection and 5\% has MDR TB (Figure $1)$.

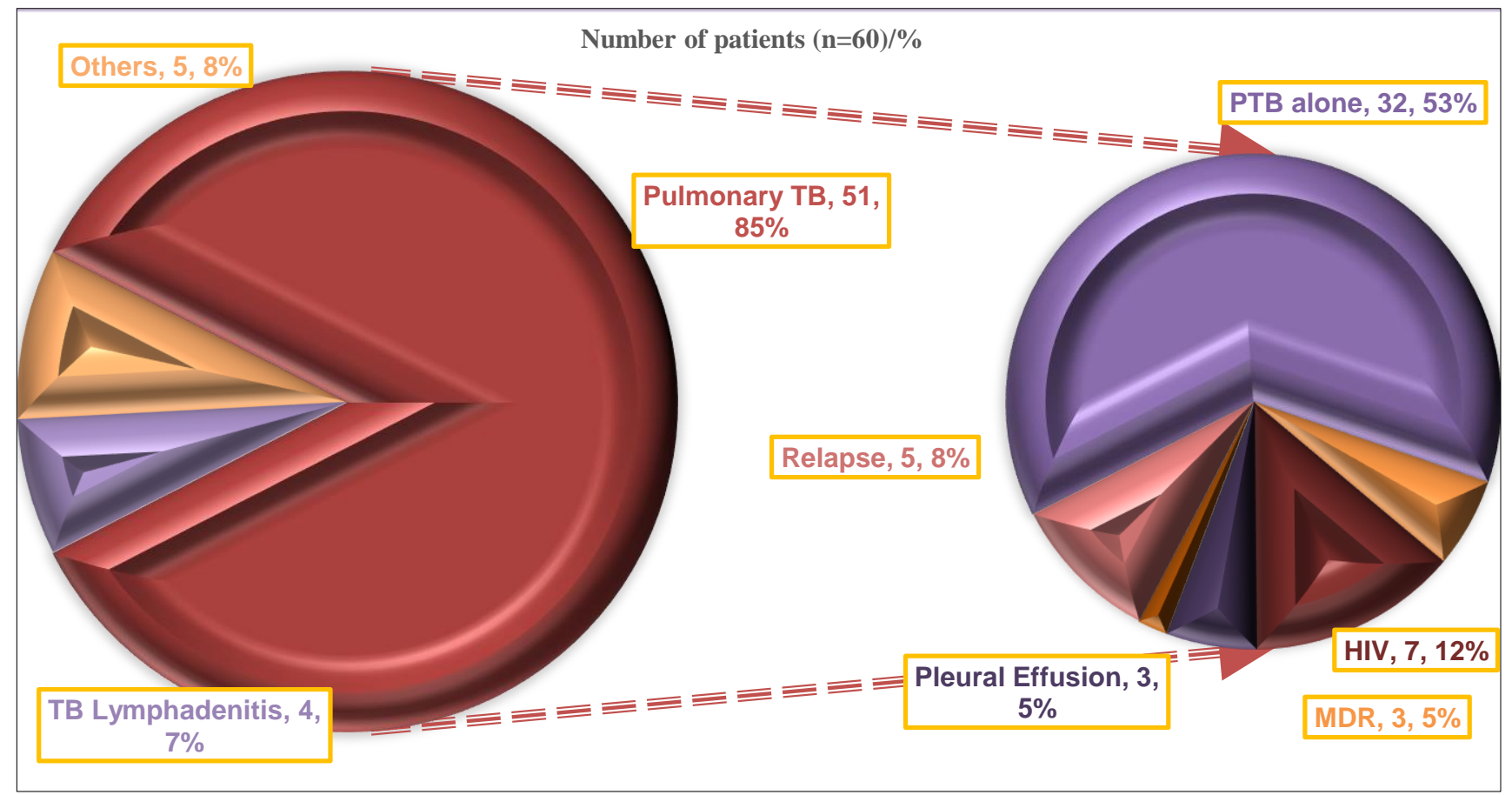

Figure 1: Clinical profile of TB patients. 
Table 1: Demographic profile of patients.

\begin{tabular}{|ll|}
\hline Demographic profile & \\
\hline Total number of patients & 60 \\
\hline Number of ADRs & 65 \\
\hline Males & $28(46.7 \%)$ \\
\hline Females & $32(53.3 \%)$ \\
\hline Mean age (years) & $43 \pm 17$ \\
\hline Mean weight (kgs) & $49 \pm 10$ \\
\hline
\end{tabular}

Table 2: WHO causality and drugs responsible.

\begin{tabular}{|c|c|c|c|c|}
\hline \multirow{2}{*}{$\begin{array}{l}\text { Adverse } \\
\text { drug } \\
\text { reaction }\end{array}$} & \multicolumn{4}{|c|}{ WHO causality scale } \\
\hline & Possible & Probable & Certain & $\begin{array}{l}\text { Total } \\
(n=65)\end{array}$ \\
\hline Hepatitis & $22(\mathrm{H} / \mathrm{R} / \mathrm{Z})$ & $2(\mathrm{Z})$ & $\begin{array}{l}1(\mathrm{Z}) \\
1(\mathrm{R})\end{array}$ & 26 \\
\hline Gastritis & $6(\mathrm{H} / \mathrm{R} / \mathrm{Z})$ & 1 (PAS) & $\begin{array}{l}1(\mathrm{Z}) \\
2(\mathrm{R})\end{array}$ & 10 \\
\hline Skin ADRs & $7(\mathrm{H} / \mathrm{R} / \mathrm{Z})$ & $2(\mathrm{R})$ & $1(\mathrm{Z})$ & 10 \\
\hline $\begin{array}{l}\text { Peripheral } \\
\text { neuropathy }\end{array}$ & $\begin{array}{l}5(\mathrm{H}) \\
1(\mathrm{AMK} / \mathrm{DCS})\end{array}$ & $3(\mathrm{H})$ & - & 9 \\
\hline Gout & $4(\mathrm{Z} / \mathrm{E})$ & - & - & 4 \\
\hline Nephritis & $1(\mathrm{R} / \mathrm{S})$ & $1(\mathrm{R})$ & $1(\mathrm{R})$ & 3 \\
\hline Ototoxicity & $\begin{array}{l}1(\mathrm{~S}) \\
1(\mathrm{AMK} / \mathrm{DCS})\end{array}$ & - & - & 2 \\
\hline Psychosis & - & $1(\mathrm{H})$ & - & 1 \\
\hline
\end{tabular}

H-Isoniazid, R-Rifampicin, Z-Pyrazinamide, E-Ethambutol, SStreptomycin, PAS-Para amino salicylic acid, AMK-Amikacin, DCS- D-Cycloserine.

Common ADRs were hepatitis (40\%), gastritis (15\%), skin reactions $(15 \%)$, peripheral neuropathy $(14 \%)$, gout (6\%) and nephritis (3\%) (Figure 2). Median duration for the onset of ADR was 31 days each for hepatitis, gout, nephritis and 20, 11, 9 days for gastritis, peripheral neuropathy and skin reactions respectively (Figure 3 ).

$77 \%$ of ADRs were observed with daily regimen (Figure 4). As per WHO causality assessment, $80 \%$ of ADRs were assigned "possible", 11\% "probable" and 9\% "certain" (Table 2, Figure 5). As per severity scale 27.7\% of ADR were severe, $36.9 \%$ were moderate, $35.4 \%$ were mild (Table 3).

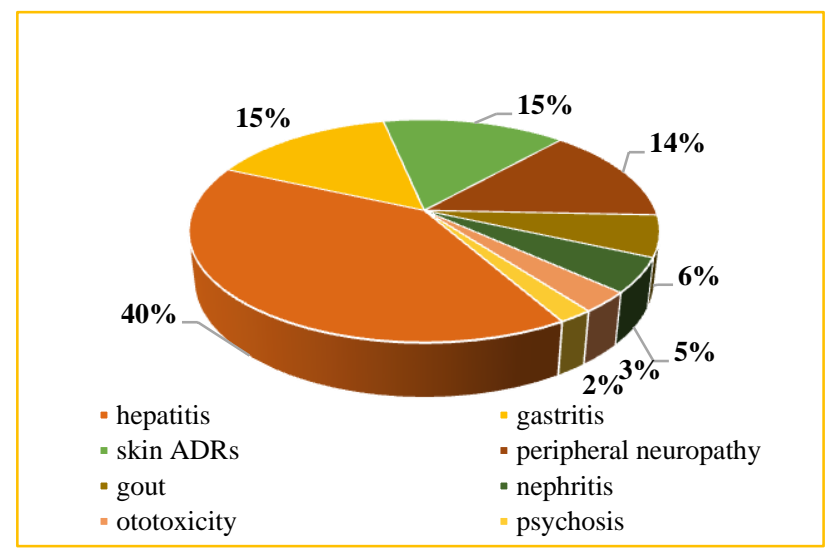

Figure 2: Adverse drug reactions $(n=65)$.

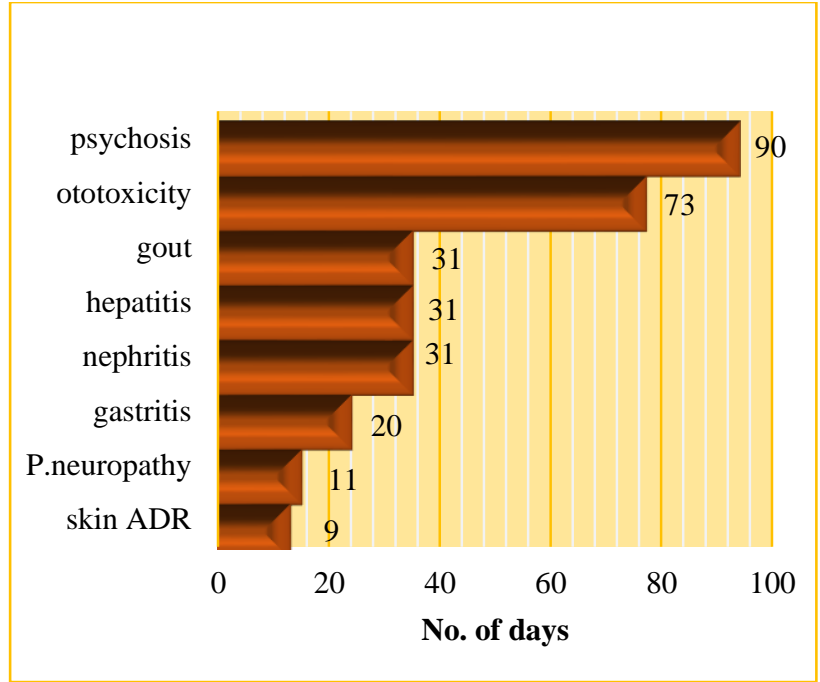

Figure 3: Median days for the onset of ADR.

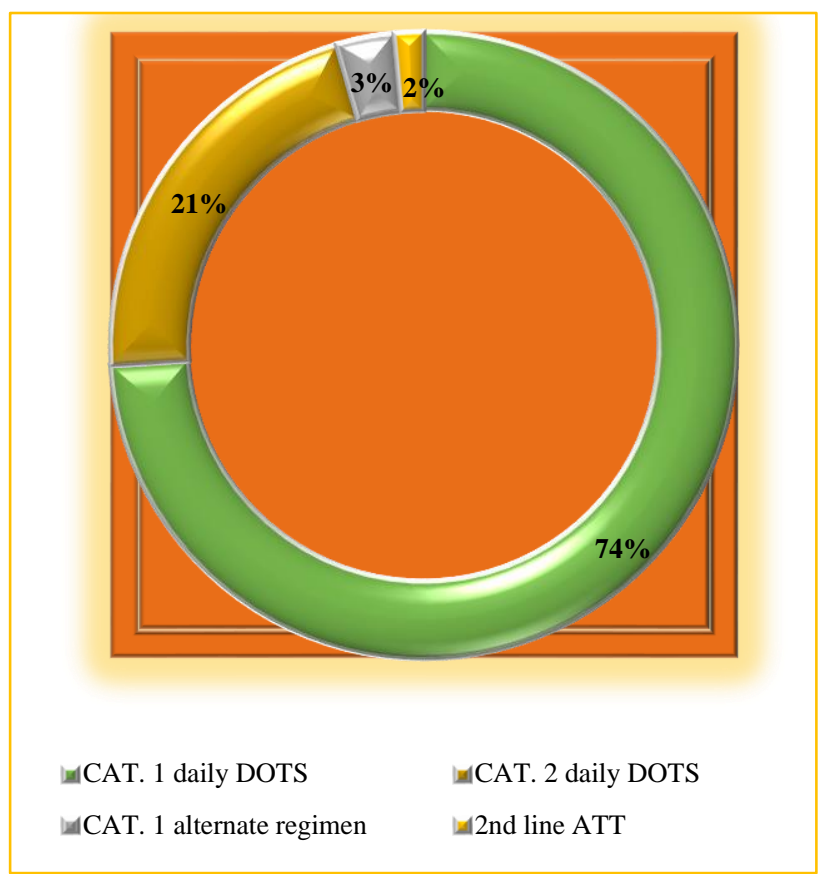

Figure 4: ATT regimen $(n=65)$.

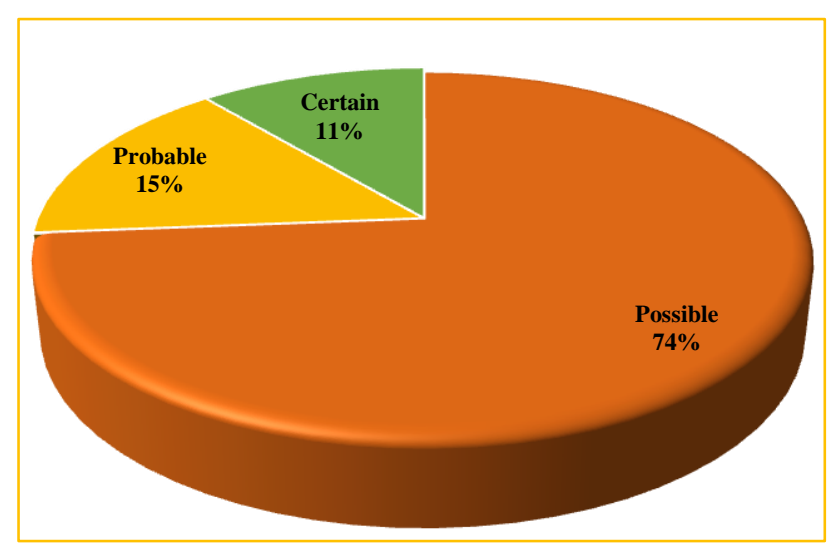

Figure 5: WHO causality scale. 
Table 3: Severity assessment of ADR using Hartwig and Siegel scale.

\begin{tabular}{|llll|}
\hline Adverse drug reactions $(\mathbf{n = 6 5})$ & Mild & Moderate & Severe \\
\hline Increased liver enzymes and hepatitis & 14 & 8 & 4 \\
\hline Dyspepsia and gastritis & 2 & 5 & 3 \\
\hline Skin ADRs & 5 & 2 & 3 \\
\hline Peripheral neuropathy & & 6 & 3 \\
\hline Arthralgia and gout & 2 & 2 & 3 \\
\hline Nephritis & - & - & 2 \\
\hline Ototoxicity & - & - & - \\
\hline Psychosis & - & 1 & $18(27.7 \%)$ \\
\hline Total & $23(35.4 \%)$ & $24(36.9 \%)$ & \\
\hline
\end{tabular}

\section{DISCUSSION}

The current study analysed the pattern of adverse drug reactions among inpatients receiving antitubercular drug therapy. The necessity of multiple drugs has been associated with increased incidence of adverse drug reactions of antitubercular drugs. About 65 adverse drug reactions were identified in 60 patients, 2 patients had multiple side effects (hepatitis and nephritis, one patient had ototoxicity in addition to this). Since the study data was collected from inpatient's case sheets that required admissions mostly due to side effects, the incidence of ADR with ATT could not be found out with the present study.

Adverse drug reactions among both sexes are almost same with a slight high female predisposition. These findings are consistent with the study results of previous studies. ${ }^{5,8-}$

${ }^{10}$ Possible reason for high prevalence of adverse drug reactions among female patients could be due to the reduced body size to body weight ratio, compared to males. Hence it is important to take precautions for females to reduce adverse drug reactions with antitubercular drug therapy.

In our study, it has been seen that majority of ADR was seen in age group of 30-50 years with a mean age of $43 \pm 17$ years. It is similar to previous studies. ${ }^{8,10}$ In our study, patients had low mean body weight which is a determinant of severity and disease outcome, could also be a risk factor for ADR.

Similar to previous studies, the majority of the cases belonged to category I daily regimen followed by Cat I alternate day regimen. ${ }^{10-12}$ It may be due to the fact that majority of $\mathrm{TB}$ cases in our study were new sputum positive cases.

In our study the most common ADRs were hepatitis along with increased liver enzymes $(15.4 \%$-severe, no fatal cases) followed by gastritis and skin ADRs. Z and R are mainly responsible for these side effects. ${ }^{10,13,14}$ Most of the ADRs developed during the intensive phase, suggesting the role of pyrazinamide. ${ }^{15,16} \mathrm{~A}$ randomized controlled trial with intermittent and daily regimens of ATT with identical dosages of pyrazinamide, showed that initial-phase intermittent regimens containing isoniazid, rifampicin, and pyrazinamide were significantly less hepatotoxic than their daily counterparts. ${ }^{15,17}$ Studies have shown that the risk of hepatotoxicity is higher in Indian patients. $^{18}$

Two cases of aminoglycoside induced sensory neural hearing loss were reported during the study period and the suspected drug was discontinued from patient drug therapy in both the cases. Confirmatory test of audiometry was done to assess ototoxicity in both patients.

Except psychosis and ototoxicity, all the ADRs had its onset during the intensive phase. In the current study, combination of HRZE was found responsible for most of the adverse drug reactions. Factors including the category of regimen, dose and dosage frequency of the drugs, genetic differences of the study population may be responsible for the ADRs. ${ }^{5}$

Most of the ADRs were moderate $(36.9 \%)$ and mild (35.4), 27.7\% were severe reaction according to Hartwig et al scale. ${ }^{7}$ Majority of the reactions were found to be moderately severe as a proper treatment measure was required even after the suspected drug was withheld, discontinued or changed.

\section{CONCLUSION}

The study results provide an insight to the healthcare providers on the importance of monitoring and reporting of adverse drug reactions in patients with tuberculosis. The pharmacovigilance program is crucial in detecting and monitoring of adverse drug reactions as it improves the patient adherence, minimizes drug resistance and thereby achieving better therapeutic outcome.

\section{ACKNOWLEDGEMENTS}

The authors would like to thank all the postgraduates and faculties, Department of Pharmacology, Medicine, 
Pulmonary Medicine, Kasturba Medical College, Manipal for their contribution to the Pharmacovigilance program.

Funding: No funding sources

Conflict of interest: None declared

Ethical approval: The study was approved by the Institutional Ethics Committee

\section{REFERENCES}

1. WHO. Global tuberculosis report 2018. Geneva: World Health Organization; 2018. WHO Publ. 2018. Available at: https://www.who.int/tb/publications/ global_report/en/. Accessed on 7th August 2019.

2. Mishra S, Jena M, Jena B, Mishra SS. A study of anti-tubercular drug induced adverse reactions in patients attending pulmonary medicine department of a tertiary care teaching hospital. Int J Pharm Sci Rev Res. 2013;21(2):308-11.

3. Chiang CY, Schaaf HS. Management of drugresistant tuberculosis. Int $\mathbf{J}$ Tuberc Lung Dis. 2010;14(6):672-82

4. Patidar D, Rajput MS, Nirmal NP, Savitri W. Implementation and evaluation of adverse drug reaction monitoring system in a tertiary care teaching hospital in Mumbai, India. Interdiscip Toxicol. 2013;6(1):41-6.

5. Shareef J, Nandakumar UP, Bhat M. A study on assessment of adverse drug reactions in patients with tuberculosis in a tertiary care teaching hospital. J Appl Pharm Sci. 2018;8(4):99-104

6. WHO UMC. The Use of the WHO-UMC System for Standardised Case Causality Assessment. Available at: http://www.whoumc.org/Graphics/24734.pdf. Accessed on 7 August 2019.

7. Hartwig SC, Siegel J, Schneider PJ. Preventability and severity assessment in reporting adverse drug reactions. Am J Hosp Pharm. 1992;49:2229-32.

8. Maqusood M, Khan FA, Swaroop A. A Study on Incidence of Adverse Drug Reaction of AntiTubercular Drugs in New Cases of Pulmonary Tuberculosis in a Tertiary Care Teaching Hospital. Int J Med Res Prof. 2016;2(3):53-6.

9. Nemagoudaa S. The antitubercular drug induced adverse effects in registered cases under RNTCP DOTS, programme in Bijapur. J Evol Med Dent Sci. 2014;3(19):5255-62.
10. Sinha K, Marak IT, Singh WA. Adverse drug reactions in tuberculosis patients due to directly observed treatment strategy therapy: Experience at an outpatient clinic of a teaching hospital in the city of Imphal, Manipur, India. J Assoc Chest Physicians. 2013;1(2):50-3.

11. Mittal C, Gupta SC. Effect of disease related variables on treatment outcome under DOTS. JK Sci 2011;13:15-8.

12. Mandal PK, Mandal A, Bhattacharyya SK. Comparing the daily versus the intermittent regimens of the anti-tubercular chemotherapy in the initial intensive phase in non-HIV, Sputum Positive, Pulmonary Tuberculosis Patients. J Clin Diagnostic Res. 2013;7(2):292-5.

13. Steele MA, Burk RF, DesPrez RM. Toxic hepatitis with isoniazid and rifampin: A meta-analysis. Chest. 1991;99:465-71.

14. Leung CC, Law WS, Chang KC, Tam CM, Yew WW, Chan CK, et al. Initial Experience on Rifampin and Pyrazinamide vs Isoniazid in the Treatment of Latent Tuberculosis Infection among Patients with Silicosis in Hong Kong. Chest. 2003;124(6):21122118.

15. Chang KC, Leung CC, Yew WW, Lau TY, Tam CM. Hepatotoxicity of pyrazinamide:Cohort and casecontrol analyses. Am J Respir Crit Care Med. 2008;177:1391-6.

16. Yee D, Valiquette C, Pelletier M, Parisien I, Rocher I, Menzies D. Incidence of Serious Side Effects from First-Line Antituberculosis Drugs among Patients Treated for Active Tuberculosis. Am J Respir Crit Care Med. 2003;167:1472-7.

17. Jindani A, Nunn AJ, Enarson DA. Two 8-month regimens of chemotherapy for treatment of newly diagnosed pulmonary tuberculosis: International multicentre randomised trial. Lancet. 2004;364:124451.

18. Taneja DP, Kaur D. Study on hepatoxicity and other side-effects of antituberculosis drugs. J Indian Med Assoc. 1990;88:278-80.

Cite this article as: Kuriachan $\mathrm{S}$, Krishnan $\mathrm{P}$, Chogtu B, George MM. Assessment of adverse drug reactions to antituberculosis regimen in a tertiary care hospital. Int J Basic Clin Pharmacol 2019;8:2202-6. 